\title{
Interdisciplinary Cultivation of Graduate Curriculum and Related Problems
}

\author{
Ruifeng Bai ${ }^{1, a^{*}}$, Jingchang Pan ${ }^{1, b^{*}}$, Gaoyu Jiang ${ }^{1, c}$ and Ali Luo ${ }^{2, d}$ \\ ${ }^{1}$ Shandong University (Weihai), Shandong 264209, China \\ ${ }^{2}$ The National Astronomical Observatories of the Chinese Academy \\ of Sciences, Beijing100012, China

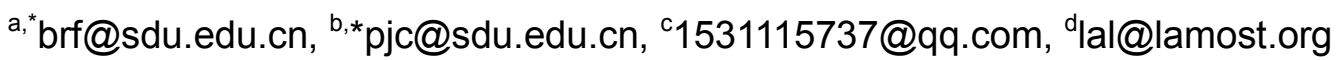

\author{
Keywords: Interdisciplinary; Postgraduate cultivation; Curriculum setting
}

\begin{abstract}
With the continuous development of science and technology, the disciplines are more and more detailed, resulting in a number of branches, and combination of similar branches has produced many edge disciplines. At the same time, multidisciplinary integration also accelerates tend of development in the modern, which have a great role in promoting the overall progress of science and technology. This kind of division and combination is a reflection of science that is without development. Therefore, there are a large number of research topics worth exploring in the field of interdisciplinary integration. Postgraduate cultivation in interdisciplinary involves two or more disciplines, so how to establish a set of effective training mechanism can not only cultivate an innovative talent team of teachers in the field of interdisciplinary training, but also ensure high quality training of graduate student in cross-disciplinary areas, is a problem worthy of further study. Researching the curriculum of the postgraduate, this paper analyzes and summarizes the problems in the course setting and puts forward suggestions, meanwhile through the analysis of the characteristics of the postgraduate education model in the United States, the school system of master's degree students is discussed.
\end{abstract}

\section{Introduction}

Interdisciplinary is a technical term which is proposed by R.S. Woodworth, a psychologist in United States Columbia University, which refers to research activities beyond single discipline. Then the interdisciplinary is not limited to research activities, as the discipline of personnel training gradually attracted the attention of the education sector. At present, domestic and foreign universities begin to explore interdisciplinary graduate training and put it into practice, which meet the need of not only research and development of science, but also the new requirements from community for talents. In order to meet the challenges brought by a series of complex problems arising from the rapid development of social economy, culture and science and technology, the graduate training mode will change from the disciplinary model to the interdisciplinary mode. According to statistics, $41.02 \%$ of Nobel Prize were born in interdisciplinary in the past one hundred years, which apparently suggests it great promotion for human social development, and only by attaching great importance to disciplinary crossing and integration can we control the direction of technological development. The practice indicates that cross-disciplinary graduate students are obviously superior to students in a single discipline in the range of scope of knowledge, scientific and technological innovation and comprehensive thinking ability, etc.

In order to adapt to the modernization and the needs of creative talents in the 21 st century, it is an urgent task for reform of higher education to reform the status of curriculum setting and academic system in colleges and universities, and set up the relevant curriculum system and content system according to the characteristics of creative talents and their development rules.

\section{Postgraduate Courses Set up Undergraduate}

Course learning is an indispensable chain in graduate education, and it's an important factor to 
ensure and improve the quality of graduate education. But now, the curriculum setting of part of the graduate cultivation units, in both content and teaching methods, has a tendency of undergraduate.

In addition to no obvious disparities from undergraduate course, the course with outmoded and course setting without consideration are also important reasons for the postgraduate course "abominable".

Today, with the acceleration of knowledge updating, courses and professional content should be constantly changing, but many courses in our domestic universities are still the old faces without change a few decades. According to what a student majoring in electrical engineering in a key university in domestic says, some of their materials used is born in the early 80 s. This situation is not uncommon.

In fact, the managers and teachers in colleges and universities are actually aware of the problems of graduate courses setting, but the update of curriculum system is a difficult system project. Once update the curriculum, it is necessary to update the teaching content, teaching materials and teaching experimental equipment, and we need to continue to invest in human, material and financial resources. At present, one of the few front-line teachers simply do not have time to carefully write teaching materials, and it's even more difficult to update the teaching laboratory equipment.

The curriculum problem actually involves the entire educational system. Considering the strength of teachers and hardware facilities, the number of graduate students in a class should be controlled within 20 people, but now, the graduate class is often the size of undergraduate class, so there is no way to have a discuss. Moreover, the root of "create a job in order to accommodate a person" is the internal management system, because teachers cannot cycle, so a teacher always arranges a course regardless of his ability. Although the assessment mechanism for teachers is now established, it is basically only possible to do the assessment in quantitative terms.

\section{Reforming the Curriculum of Colleges and Universities}

The course of higher education is the main channel for our schools to realize the cultivation of students' creativity. However, as mentioned above, this common goal of higher education in China has been always unclear or not prominent, leading the curriculum of higher education generally incompatible with the goal of cultivating creative quality.

Up till the present moment, universities are still very vague or at low level on the awareness of choosing teaching content and setting up the course according to the goal. the curriculum and the content selection are also ambiguous even if the goal of cultivating is clear. The main performances are as follows:

Firstly, the natural continuation of traditional courses. Naturally Inherit the courses which the schools or departments have in the past. The teachers of these courses coach for decades, and they bring out a group of successor teachers, or schools refer to or transplant other schools' similar professional courses, which make it difficult to adjust courses to the target.

Secondly, courses setting depends on what kinds of teacher school have hired. This is a way for many colleges and universities to set up courses, which is also another form of the first problem. As there are not suitable teachers for the course, schools have to use a similar course to replace it, which will inevitably make the course skewed. Like "history of science" is replaced by "history of physics", and "artistic principles" becomes into "literary principles" and so on. Especially in elective courses, if teachers are interested in a field of knowledge and have a certain degree of research, or teachers have a certain degree of visibility, and they can set up this lesson, rarely considering the relationship between courses andthe relationship between course and goal of cultivating.

Thirdly, there are too many courses that provide knowledge while too less provide skills (training of thinking and behavior), and even some skilled based courses are set up and taught according to a knowledgeable curriculum and eventually become a knowledgeable course.

Fourth, the division of knowledge courses is obvious, and interdisciplinary courses are rare. The absolute isolation of the knowledge of the various disciplines seriously blockedthe formation of 
students' wide and profound knowledge structure and the formation of creative thinking.

At present, many colleges and universities have recognized that the division of courses, especially the absolute separation of liberal art and science, is defective, and begin to adopt some new method of cross integration of science and art courses, such as the department of liberal arts offers "higher mathematics", "dialectics of nature" and "Introduction to the natural sciences", and department of science adds classes like "aesthetics"," aesthetic education" or "art appreciation". There is no doubt that this kind of cross integration of science and art courses is a great progress of curriculum construction in Chinese colleges and universities at the end of the 20th century. However, As the educational goals are unclear, the relationship between creative talents, "creative" goals and the knowledge of the disciplines is unclear. Some of the interdisciplinary and integrated courses are still far from achieving the desired goals.

\section{Some Suggestions on the Curriculum of Postgraduate}

The training program is basis of graduate education, and curriculum is an important part of training programs, which is reification of the basic theory of graduate students and the specific requirements of specialized knowledge learning. Therefore, with revising the curriculum and improving the syllabus as the core, we extended to optimize the training program, build a high level team of teachers, introduce and write outstanding graduate teaching materials, perfect the quality of graduate training system and evaluation system, strengthen the overall quality of education and establish a unique science education system that is more adaptable to the cultivation of innovative talents.

The revision of curriculum and syllabus is a comprehensive system project. We should focus on the need of the modernization of our country in $21^{\text {st }}$ century for all kinds of high-level professionals. Based on improving the cultivation quality of graduate students, especially the innovation ability and comprehensive quality, we should pay attention to both the characteristics and the overall strength, further to the construction of the basic courses of the first class disciplines, and strengthen the courses about humanities, social sciences and management science.

Taking full account of the need of graduate student in applied discipline of high and new technology, emerging disciplines, interdisciplinary and their elective scope, adding interdisciplinary courses, methodology courses, innovative ability training courses, humanities social sciences and management courses, the curriculum should be based on discipline, covering main disciplines of the major. Through learning the courses, graduate students will have a reasonable knowledge structure and get a comprehensive ability of using the knowledge, innovation and organizational management, which will lay a solid foundation for the future research on innovative scientific research, high level education, economy and society. In addition to public compulsory courses, public elective courses, each discipline is divided into basic courses, discipline comprehensive courses, professional basic courses, specialized courses according to different attributes of course. Professional basic courses and basic courses of the discipline are basic theoretical courses of the discipline. According to the secondary disciplines within the scope of their first class discipline to expand, paying attention to the characteristics of the secondary disciplines and their knowledge structure, focusing on systematicness and fundamentality, we can lay a solid foundation for graduate students. Professional courses focus on cutting-edge and innovation, reflecting the development of the interdisciplinary, marginal disciplines and emerging disciplines, adapting to the meet requirements of high, refined and deep for training high-level specialized talents, tracking the development of disciplines and social needs, so that graduate students can grasp the latest developments of the subject and the need of economic construction and social development. The discipline comprehensive courses introduce the history, current situation and prospect of the development of the subject, which makes graduate students can understand the development of the subject and the connection with other disciplines. The public elective courses focus on cultivating the comprehensive quality of postgraduates such as humanities, management, society and environment consciousness, and cultivate the abilities of mathematics, English to listen, speak, read and write, and computer skills, which makes graduate students get all-round development in the "moral, 
intellectual, physical, aesthetic, energy".

\section{Acknowledgements}

The research is sponsored by The Natural Science Foundation of China (U 1431102).

\section{References}

[1] Gao J Q, Zheng H, Quan-Hong Y U, et al. Deliberate Practice in the Cross-discipline Establishment and Graduate Education --A Case Study on Sun Yat-sen University[J]. Higher Education Forum, 2(2015):98-101.

[2] LvX F, Fan H M, Wu W. The Compound Mentorship Conception of Interdisciplinary Postgraduate Cultivation [J]. Research Institute of Development Strategy. 11(2015):33-39.

[3] Wang Y Y, Gao L. The training model and characteristics of interdisciplinary graduate students in Purdue University [J]. Journal of World Education. 4(2015):36-40.

[4] Han X Y, Zhao M S, Yi-Ying G U, et al. Study of the innovative ability cultivation for postgraduates based on the crossing between optical engineering and multi- disciplines [J]. Laboratory Science. 18.4(2015):5-9.

[5] Xue Y W. Exploration on the cultivation mode of Interdisciplinary Graduate Students, Leadership Science Forum [J]. 23(2015):34-35.

[6] Xue X Y. Cultivating Innovative Ability of Linguistics Postgraduates under the Interdisciplinary Background [J]. Journal of Wuling. 40.6(2015):133-136.

[7] Zhu X M, Xiang X. Research on the training mode and evaluation system of Interdisciplinary Graduate Students--A Case Study on industrial engineering [J]. Education Teaching Forum. 39(2015):146-149. 